\title{
Foreword to the special issue on IS sourcing
}

\author{
Rudy Hirschheim • Jens Dibbern • Armin Heinzl
}

Published online: 13 February 2008

(C) Springer Science + Business Media, LLC 2008

The issue of information systems (IS) sourcing has been an area of interest of the IS community for almost two decades now. IS sourcing refers to the entire set of processes ranging from initiating and preparing the decision to provide an organization's IS function(s) in-house or externally by a legally independent service provider (or some combination of the two options); making the decision; implementing the decision; and evaluating and potentially changing or confirming (i.e. renewing) the decision. The reason for the continued interest in IS sourcing is closely related to the steady change of the phenomenon itself. While in the early 1990s the interest in IS sourcing gained momentum by the appearance of IS outsourcing megadeals involving clients such as Kodak (Applegate and Montealegre 1991), Continental Bank (Huber 1993) and BP (Cross 1995) with providers such as Electronic Data Systems and International Business Machines, now new forms of outsourcing arrange-

\footnotetext{
R. Hirschheim $(\bowtie)$

Department of Information Systems and Decision Sciences, Louisiana State University,

Baton Rouge, LA 70803, USA

e-mail: rudy@1su.edu

J. Dibbern

Department of General Management and Information Systems, University of Mannheim,

Schloss, S 135,

68131 Mannheim, Germany

e-mail: dibbern@uni-mannheim.de

\section{A. Heinzl}

Department of General Management and Information Systems, University of Mannheim,

Schloss, S 219/220,

68131 Mannheim, Germany

e-mail: heinzl@uni-mannheim.de
}

ments (such as selective outsourcing, joint ventures, strategic alliances, and spin-offs), stories of successes and failures, decisions to backsource, as well as a variety of innovative approaches for developing and managing outsourcing relationships have led to an ever increasing complexity of the phenomenon.

This complexity of the IS sourcing phenomenon is mirrored by a multitude of academic research studies on the topic. In a comprehensive literature review, Dibbern et al. (2004) identified 81 academic papers that were published from 1992 to 2001 in refereed conference proceedings and academic journals. Based on an analysis of the diversity of research, reflected in various research objectives, research approaches and theoretical foundations, they highlighted a number of research gaps and emergent themes that should be addressed by future research. Today, we are pleased to note that many of these directions for future research have been taken up by researchers. Indeed, the research landscape of IS sourcing is flourishing more than ever before. We note that many unresolved issues around the traditional IS outsourcing phenomenon are being or have been addressed. On the other hand, new phenomena have appeared on the outsourcing landscape. As such the IS outsourcing phenomenon has moved beyond the boundaries of the IS function to include entire information technology (IT)-supported business processes (so called business process outsourcing (BPO)) as well as beyond national boundaries signaled by the increasing practice of handing over IS services to vendors located in low wage counties such as India, China and Russia (Carmel and Tjia 2005).

This special issue on IS sourcing provides a collection of research studies that have either addressed one or more of the research gaps in traditional IS outsourcing or addressed one or more of the emergent phenomena such as IS offshoring or BPO as noted in Dibbern et al. (2004). These 
papers are based on the research presented by a subset of participants attending the 3rd International Conference on Outsourcing of Information Services (www.ICOIS.de) which was held in Heidelberg, Germany, May 29 to 30, 2007. Conference participants were asked if they wished to contribute to this special issue and a number of them agreed. Submissions were then refereed for quality and suitable content. This special issue is the outcome of the process.

Nine papers make up this special issue. Five of the nine papers focus on research questions of traditional IS outsourcing. They deal with questions such as why firms outsource IS functions, what determines the success of IS outsourcing arrangements, how IS outsourcing influences firm performance and what types of capabilities are needed by IS service providers for managing IS outsourcing relationships.

The initial sourcing decision is explored in Aubert, Beaurivage, Croteau, and Rivard. They examine how the IS souring decision is influenced by firm strategy. As such, they contribute to overcoming the apparent lack of a cumulative research tradition in the field of IS outsourcing (see Dibbern et al. 2004) by replicating the linkage between firm strategy and degree of outsourcing as tested in previous research (Grover et al. 1994). Moreover, the comparison of IT operations and maintenance outsourcing contributes to a stronger recognition of functional differences.

The next three papers are concerned with the outsourcing relationship and how its appropriate management may lead to higher levels of IS outsourcing success. Lee, Huynh, and Hirschheim focus on the concept of knowledge sharing between client and vendor personnel as a main prerequisite for successful outsourcing arrangements and how knowledge sharing is enabled by mutual trust. One of the unique features of this study is the recognition of both the vendor and the client side which is included in the empirical comparison. This paper thus examines outsourcing success from both perspectives. Moreover, the authors add a temporal dimension to the phenomenon by distinguishing between initial and current trust in outsourcing relationships. This study is valuable because the vendor perspective has rarely been accounted for in previous research (also see Levina and Ross 2003).

The explicit recognition of temporal dynamics in outsourcing relationships makes up the key contribution of the study by Fisher, Hirschheim, and Jacobs. Their study is one of the first with a longitudinal perspective. By analyzing the outsourcing endeavor of a single firm at three different points in time over a period of 9 years, they are able to show how changes in the objectives associated with outsourcing lead to different responses in the management of the outsourcing relationship and hence in the success factors of IS outsourcing.

The study by Goles, Hawk, and Kaiser focuses on one particular success factor of outsourcing relationships, viz. the capability of the service provider. More specifically, they examine the particular skill sets that are required by IT- firms now and in the future. Their study is rare in that it takes a vendor perspective as well as in the detail in which the skills of IT professionals are analyzed. Also illuminating is the comparison of required skill sets from the perspective of IT firms and non-IT firms. These differences have implications for the design and implementation of the different possible roles for client and vendor firms.

The study by Straub, Weill, and Schwaig goes beyond the outsourcing relationship as the unit of analysis by considering how IS outsourcing is related to overall firm performance. Other than prior research that examined the direct impact of the degree of IS outsourcing on firm performance, they argue that outsourcing reduces the level of control over the IT resource and accordingly needs to be aligned with the strategic importance that an organization attributes to its IT function(s).

The next four studies go beyond traditional IS outsourcing by addressing BPO and offshoring. However, that does not mean that they are unrelated to the stream of research on traditional IS outsourcing. Indeed the study by Wüllenweber, Beimborn, Weitzel, and König can also be categorized under the broad label of studies on outsourcing success factors. Their study is unique in examining the outsourcing of entire business processes rather than the IS function, and also by examining the role of standardization as a key determinant of BPO success. Drawing on economic theories and relational exchange theory, they test three alternative explanations for the impact of standardization on BPO success.

The last three papers of the special issue are concerned with the IS offshoring phenomenon. All three focus on offshore outsourcing to service providers in India. But each paper takes a different perspective. One looks at offshoring from the viewpoint of the Indian vendor, one takes the perspective of a client from the US, and one paper takes the view of German client organizations.

Lacity, Iyer, and Rudramuniyaiah concentrate their analysis on one particular challenge that is often neglected in the discourse of offshore outsourcing: i.e. the high level of employee turnover. Based on expert interviews with Indian IS professionals they seek to identify the main reasons for turnover intentions. They find some interesting offshore specific features that call for a number of adaptations of factors and relationships that were found to be of relevance in previous research studies in the context of traditional non-offshore settings.

Another challenge that is frequently mentioned when it comes to offshore outsourcing are the cultural differences between client and vendor country. This challenge is the focus of the study by Winkler, Dibbern, and Heinzl. They examine the impact of cultural differences between Germany and India on the success of software development projects that were offshored to Indian vendors by German client organizations. A number of cultural themes were identified that are related to established cultural dimensions as 
distinguished in different norms and values of cultural groups. These cultural differences are found to impact established outsourcing success factors such as mutual trust, cooperation, avoidance of conflicts and vendor performance.

Finally, Rottman and Lacity examine how certain situational factors are related to the success of offshore outsourcing projects. The study makes an important contribution to a better understanding of offshore outsourcing success factors by identifying two categories of situational factors that explain variations in the success of offshored IS projects. The authors note that the characteristics of the client, such as its former social ties with domestic outsourcing vendors, its organizational culture and its project management processes and expectations can have an impact on the relationship with the offshore vendor and, thereby, impact the success of the project. But they also note that specific project properties, such as the size of the vendor, the duration of the contract, the value of the contract, or the type of the IS function that is offshored, can also influence offshore outsourcing success.

Overall, we are happy to have had the opportunity to bring together scholars from around the world who have adopted a variety of perspectives to examine the phenomena of IS outsourcing, BPO and IS offshoring. All nine papers in the special issue are empirical in nature and due to the diverse cultural background of the authors, the empirical data stems from a wide variety of cultural backgrounds, such as the US, Canada, Germany, Korea, and India. We also note a fruitful balance of empirical research methods including qualitative and quantitative methods as well as a longitudinal perspective which goes beyond the still predominant cross-sectional approach. The set of papers in the special issue makes a substantial contribution in enhancing our understanding of the increasingly complex phenomenon of IS sourcing. These papers also open up a variety of avenues for future research into IS sourcing which we hope will spur further work in this important area. We trust the reader will enjoy this special issue.

\section{References}

Applegate, L., \& Montealegre, R. (1991). Eastman kodak organization: Managing information systems through strategic alliances. Harvard Business School Case 9-192-030. Boston: Harvard Business School.

Carmel, E., \& Tjia, P. (2005). Offshoring information technology: Sourcing and outsourcing to a global workforce. Cambridge: Cambridge University Press.

Cross, J. (1995). IT outsourcing: British petroleum. Harvard Business Review, 73, 94-102 May-June.

Dibbern, J., Goles, T., Hirschheim, R., \& Jayatilaka, B. (2004). Information systems outsourcing: A survey and analysis of the literature. The DATA BASE for Advances in Information Systems, 35(4), 6-102.
Grover, V., Cheon, M. J., \& Teng, J. T. C. (1994). An evaluation of the impact of corporate strategy and the role of information technology on IS functional outsourcing. European Journal of Information Systems, 3(3), 179-190.

Huber, R. (1993). How continental bank outsourced its 'Crown Jewels'. Harvard Business Review, 71(1), 121-129 JanuaryFebruary.

Levina, N., \& Ross, J. (2003). From the Vendor's perspective: Exploring the value proposition in IT outsourcing. MIS Quarterly, 27(3), 331-364.

Rudy Hirschheim is the Ourso Family Distinguished Professor of Information Systems at Louisiana State University. He has previously been on the faculties of University of Houston, Templeton College Oxford, London School of Economics and McMaster University. His $\mathrm{PhD}$ is from the University of London. He was awarded an honorary doctorate by the University of Oulu (Finland) and is Fellow of the Association for Information Systems. His articles have appeared in numerous academic and practitioner journals including: $M I S Q, I S R$, JAIS, JMIS, Journal of Marketing, EJIS, ISJ, JSIS, AMIT, ACM Computing Surveys, CACM, CAIS, ISF, Sloan Management Review and California Management Review. He is Co-consulting Editor of the Wiley Series in Information Systems. He is Senior Editor of Journal of the Association for Information Systems; on the editorial boards of the journals: Information and Organization; Information Systems Journal; Journal of Strategic Information Systems; Journal of MIS; and Journal of Information Technology.

Jens Dibbern is an Assistant Professor in information systems at the School of Business at the University of Mannheim, Germany. He received his Ph.D. in information systems from the University of Bayreuth, Germany in 2003 and was awarded with the Alcatel SEL dissertation prize for outstanding performance. His research has focused on outsourcing and the industrialization of application software services. His papers have appeared in WIRTSCHAFTSINFORMATIK, Zeitschrift für Betriebswirtschaft, MIS Quarterly, and The Data Base for Advances in Information Systems. He serves as a senior editor of Data Base.

Armin Heinzl is Professor and Chair of Business Administration and Information Systems at the University of Mannheim, Germany. His research and teaching interests are process technologies, information systems outsourcing and collaborative software engineering. He has held visiting positions at Harvard, Berkeley, and Irvine. His papers have appeared in WIRTSCHAFTSINFORMATIK, Zeitschrift für Betriebswirtschaft, Die Betriebswirtschaft, MIS Quarterly, Information Systems and E-Business Management, Journal of Organizational Computing and E-Commerce, and Evolutionary Computation. $\mathrm{He}$ is a member of the editorial board of the journal WIRTSCHAFTSINFORMATIK and Department Editor of the Zeitschrift für Betriebswirtschaft. 